\title{
Optimalisasi Kemampuan Kader TB dalam Pengendalian Tuberkulosis
}

\author{
Iskandar Arfan $^{1 *}$, Ayu Rizky ${ }^{2}$, Syarif Rizky Alkadri ${ }^{3}$ \\ ${ }^{123}$ Program Studi Kesmas, Universitas Muhammadiyah Pontianak \\ E-mail*: Iskandar.arfan@unmuhpnk.ac.id
}

\begin{abstract}
Article History:
Received: Desember

Revised: Desember

Accepted: Desember

Available online:

Desember
\end{abstract}

Kata Kunci: Kader, Pengendalian, Tuberkulosis,

\begin{abstract}
Abstrak:
Data laporan bulanan puskesmas Sui Kakap Kabupaten Kuburaya kasus Tuberkulosis (TB) masih menjadi permasalahan dan cenderung mengalami kenaikan kasus. Desa kalimas merupakan salah satu desa yang memberikan sumbangsih kasus TB di wilayah kerja puskesmas Sui Kakap. Dalam hal penanganan penyakit TB, kader bertindak sebagai rujukan penderita ke puskesmas setempat sehingga penemuan dan penanganan serta pengendalian TB dapat segera ditanggulangi. Untuk mengoptimalkan fungsi kader di perlukan penguatan kader baik dari jumlah dan informasi sehingga peran kader lebih optimal, memiliki capaian kinerja dan memudahkan evaluasi. Mitra kegiatan ini adalah 10 kader TB di Desa Kalimas. Pelatihan dengan metode edukasi dan pelatihan dengan penguatan informasi $\mathrm{TB}$, fungsi kader, keterampilan berkomunikasi, serta keterampilan pencatatan dan pelaporan TB. Hasil kegiatan ini menunjukkan adanya peningkatan pengetahuan pada kader, kemampuan komunikasi kader TB, Kemampuan pencatatan dan pelaporan kader TB. Disarankan Pihak puskesmas dapat selalu memantau dan mengevaluasi kinerja kader sehingga penularan dan pengendalian $\mathrm{TB}$ dapat ditekan melalui peran optimal kader.
\end{abstract}




\section{Pendahuluan}

TBC (Tuberkulosis) yang juga dikenal dengan TB adalah penyakit paruparu akibat kuman Mycobacterium tuberculosis. Secara global pada tahun 2018 terdapat sekitar 9 hingga 11,1 juta kasus insiden TB yang setara dengan 132 kasus per 100.000 penduduk. Lima negara dengan insiden kasus tertinggi yaitu India, China, Indonesia, Philipina, dan Pakistan. (WHO, 2019).

Situasi TB di indonesia tahun 2018 (data per 1 mei 2019) sebanyak 842.000 kasus. Dengan angka notifikasi kasus sebanyak 569.899 sisanya 32\% belum terlaporkan. Mereka yang belum ditemukan menjadi sumber penularan TB di masyarakat. Ditambah dengan muncul tantangan baru bagi pengendalian TB, misalnya ko-infeksi TB-HIV, TB resistan obat (TB-RO), TB kormobid, TB pada anak dan tantangan lain dengan tingkat kompleksitas yang makin tinggi (Kemenkes RI, 2020)

Berdasarkan Laporan seksi Pencegahan \& Pengendalian Penyakit Menular Dinas Kesehatan Provinsi Kalimantan Barat, jumlah kasus baru TB BTA + atau ditemukan bakteri tahan asam pada sampel dahak orang yang diduga TB sebanyak 4.444 kasus dengan angka insidens 88,85 per 100.000 penduduk. Sedang untuk persentase kesembuhan penderita TB Paru dengan BTA positif di Kalimantan Barat adalah sebesar 69,3\%, dengan rincian dari 3.709 penderita yang diobati, sebanyak 3.312 penderita dinyatakan sembuh (Dinas Kesehatan Provinsi Kalimantan Barat, 2019)

Kuburaya merupakan salah satu kabupaten yang memberikan sumbangsih terhadap kasus baru TB di Kalimantan Barat. Data laporan bulanan puskesmas sui kakap mencatat jumlah kasus TB pada tahun 2016 sebanyak 39 kasus, tahun 2017 sebanyak 53 kasus, tahun 2018 sebanyak 55 kasus (Puskesmas sui kakap, 2018)

Strategi nasional dalam mengendalikan TB yakni dengan (1) Penguatan kepemimpinan program TB, (2)Peningkatan akses layanan TB yang bermutu, (3) Pengendalian faktor risiko TB.(4) Peningkatan kemitraan TB, (5) Peningkatan kemandirian masyarakat dalam penanggulangan TB, dan (6) Penguatan manajemen program TB (Kemenkes RI, 2017)

Pemberdayaan masyarakat dengan Kader TB memiliki peran penting terutama dalam upaya penemuan, pemberian informasi dan pendampingan 
pasien TB. Dalam hal penanganan penyakit TB, kader bertindak sebagai rujukan penderita ke puskesmas setempat sehingga penemuan dan penanganan serta pengendalian TB dapat cepat di lakukan.

Kader TB di Desa Kalimas sudah terbentuk namun kinerjanya dapat dikatakan belum optimal dimana kader masih belum punya capaian kinerja yang jelas, dalam pengabdian dosen melalui lembaga penelitian dan pengabdian muhammadiyah (LPPM).

Pelatihan ini bermanfaat agar kader dapat optimal dalam memberikan informasi dan pendampingan TB, memiliki kemampuan berkomunikasi dan memiliki kemampuan dalam melakukan pencatatan dan pelaporan TB yang dapat dievaluasi, sehingga penularan dan pengendalian TB dapat ditekan melalui peran optimal kader.

\section{Metode}

Metode pelaksanaan kegiatan ini dilakukan dengan pemberian edukasi dan pelatihan. Kegiatan ini dilakukan pada 10 kader di Desa Kalimas Kabupaten Kubu Raya Kalimantan Barat Kamis 27 Agustus 2020. Kegiatan pengabdian di mulai dengan koordinasi kepada kepala desa kalimas, pemegang program TB puskesmas, kepala puskesmas, terkait perencanaan optimalisasi kader TB di desa kalimas. Selanjutnya mengundang kader TB untuk sosialisasi mengenai TB dan peran kader TB, pelatihan komunikasi dan pencatatan pelaporan TB. Untuk mengevaluasi fasilitator memberikan kuesioner pre dan posttest setelah sosialisasi, peserta diberikan kesempatan mengisi kuesioner sebelum penyuluhan dan setelah penyuluhan masing-masing selama 10 menit kemudian mengevaluasi kemampuan kader tentang komunikasi dan pelaporan TB dengan lembar keberhasilan indikator keterampilan. Untuk penjelasan masing-masing kegiatan yakni :

1. Sosialisasi dan penyegaran informasi

Kegiatan sosialisasi dilakukan dengan menggunakn metode ceramah dan Tanya jawab dalam kegiatan ini peserta diberikan pengetahuan dan penyegaran informasi mengenai tuberkulosis, penyebab tuberkulosis, gejala $\mathrm{TB}$, penularan TB, jenis TB, kelompok pasien TB, pemeriksaan TB, Pengobatan TB, efek samping obat TB, Pencegahan TB, Kader TB dan peran kader TB. 


\section{Pelatihan komunikasi kader TB}

Kegiatan pelatihan komunikasi kader TB di lakukan dengan menggunakan metode ceramah dan role play. Pada kegiatan ini sosialisasi dilaksanakan di aula pertemuan yang dihadiri oleh kader TB wilayah kerja Puskesmas Sui Kakap. Dalam pelatihan diberikan informasi dan tips cara berkomunikasi yang baik, dan memiliki kemampuan memberikan penyuluhan. Dimana semua kegiatan ini dapat memberi bekal kepada kader dalam mengoptimalkan peran nya sebagai kader TB aktif di wilayah kerja masing-masing.

3. Pelatihan pencatatan dan pelaporan TB

Pelatihan ini bertujuan agar kader memiliki keterampilan dan skill dalam membuat catatan dan pelaporan untuk TB. Capaian dan kinerja jelas meliputi jumlah masyarakat yang di edukasi, capaian suspek yang di rujuk ke fasilitas pelayanan kesehatan, capaian pasien TB yang didampingi, Pasien TB yang berhasil sembuh selama pendampingannya.

4. Evaluasi

Sosialisasi dan pelatihan dievaluasi dan diberikan kriteria keberhasilan dengan menggunakan indikator pretest-posttest dan keberhasilan indikator keterampilan.

\section{Hasil}

Pengetahuan tentang tuberkulosis dan peran kader sangat penting untuk mendukung kader dalam usaha penemuan kasus suspek TB dan mengetahui fungsi kader TB dalam usaha pengendalian TB. Dari skor preposttest dari 15 pertanyaan pengetahuan TB dan peran kader TB didapatkan peningkatan pengetahuan sebelum dan setelah dilaksanakan pelatihan. Kenaikan tingkat pengetahuan kader tentang TB dari skor rata-rata 6,2 menjadi rata-rata 12,9 . Perubahan ini sangat signifikan mengingat kader beberapa sudah lama tidak aktif dan dengan penyegaran pengetahuan dapat mempengaruhi peningkatan pengetahuan kader tentang TB, dan peran kader $\mathrm{TB}$, Untuk lebih detail skor tiap individu dapat dilihat pada tabel 1 dibawah ini mengenai hasil rekapitulasi skor pengetahuan kader tentang TB dan peran kader TB sebelum dan sesudah penyuluhan. 
Tabel 1. Rekap hasil pretest dan Pos test

\begin{tabular}{lccc}
\hline \multicolumn{4}{c}{ Skor Pre-Test dan Pos-Test Kader TB } \\
\hline NO & Inisial & Sebelum & Sesudah \\
& Kader & & \\
\hline 1 & NW & 7 & 12 \\
\hline 2 & SBH & 5 & 11 \\
\hline 3 & MRN & 6 & 12 \\
\hline 4 & RK & 8 & 11 \\
\hline 5 & MR & 7 & 15 \\
\hline 6 & YA & 6 & 14 \\
\hline 7 & YLT & 6 & 12 \\
\hline 8 & LN & 5 & 13 \\
\hline 9 & YN & 5 & 15 \\
\hline 10 & SYN & 7 & 14 \\
\hline \multicolumn{5}{c}{ Rata } & 6,2 & 12,9 \\
\hline
\end{tabular}

Untuk Pelatihan komunikasi, pencatatan dan pelaporan TB, Kader di bagi menjadi 4 kelompok kemudian diberikan pelatihan komunikasi, pencatatan dan pelaporan TB. Setelah diberikan pelatihan peserta diberikan kesempatan diberikan kesempatan mendemontrasikan pengetahuan dan keterampilan yang di dapat kemudian peserta di nilai keterampilan nya menggunakan skor keterampilan, dapat dilihat dari gambar 1 dan tabel 2 di bawah ini.

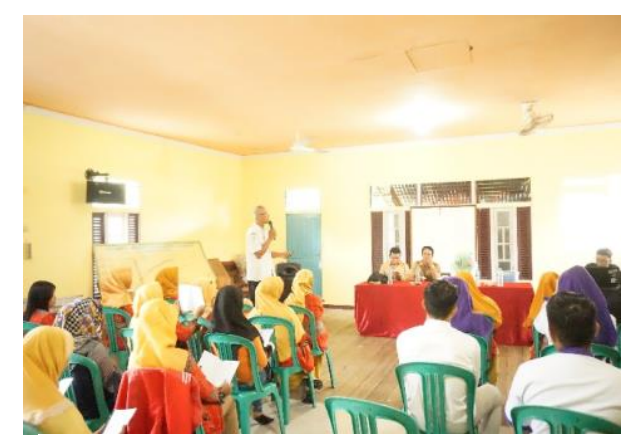

Gambar 1. Pelatihan kader TB 
Tabel 2. Evaluasi Pencatatan dan Pelaporan

\begin{tabular}{llllll}
\hline \multirow{2}{*}{ No } & Keterampilan & \multicolumn{5}{c}{ Kelompok } \\
\cline { 2 - 6 } & A & B & C & D \\
\hline 1 & $\begin{array}{l}\text { Persiapan } \\
\text { Peralatan } \\
\text { Pencatatan }\end{array}$ & 4 & 4 & 4 & 4 \\
\hline 2 & $\begin{array}{l}\text { Ketepatan } \\
\text { Pencatatan dan } \\
\text { pelaporan }\end{array}$ & 4 & 4 & 3 & 4 \\
\hline 3 & $\begin{array}{l}\text { Keterampilan } \\
\text { komunikasi }\end{array}$ & 4 & 4 & 4 & 3 \\
\hline & Total Skor & 12 & 12 & 11 & 11 \\
\hline 4=sangat baik, 3=baik, 2=cukup, 1=kurang \\
\hline
\end{tabular}

Dari data diatas diketahui bahwa setelah pelatihan 4 kelompok peserta semuanya memiliki keterampilan sangat baik dalam persiapan peralatan pencatatan, dalam ketepatan pencatatan 3 kelompok memiliki keterampilan sangat baik dan 1 kelompok memiliki keterampilan baik, Sedangkan dalam keterampilan komunikasi 3 kelompok memiliki keterampilan sangat baik dan 1 kelompok memiliki keterampilan baik.

\section{Diskusi}

Semakin tinggi pengetahuan kader maka semakin banyak penemuan suspek TB Paru. Kondisi ini terkait dengan kecakapan yang dimiliki kader, pengetahuan yang baik akan mendorong kader semakin cakap dalam menemukan suspek TB Paru (Wahyudi, 2010). Penelitian Al Maniri, et al (2008) dalam penelitian nya mengenai pengetahuan suspek TB pada para petugas menyatakan bahwa keberhasilan penemuan suspek TB paru berkaitan dengan pengetahuan tentang cara penemuan itu sendiri, tanpa adanya pembekalan kepada petugas cenderung menyebakan cakupan penemuan semakin rendah. Dalam memudahkan proses penemuan kasus pengetahuan kader sangat penting karena berkaitan dengan kemampuan kader untuk mengenali tanda-tanda suspek TB (Al-Maniri et al., 2008). Pelatihan kader TB erat kaitannya dengan penanganan tuberculosis diperlukan pelatihan 
secara kontinu untuk menambah wawasan kader, seperti penelitian yang dilakukan oleh (Boy et al., 2015) dalam penelitian nya mengenai efektifitas pelatihan kader kesehatan dalam penanganan tuberculosis dimana pengetahuan kader Kesehatan secara signifikan meningkat setelah pelatihan manajemen TB. Maka poin penting disini adalah bahwa pemahaman kader tentnag TB dan pemahaman kader terkait peran akan mempermudah kader dalam melakukan upaya penemuan kasus serta pencegahan TB di lapangan.

Pelatihan kader tentang Komunikasi dan pencatatan pelaporan TB di butuhkan oleh kader dalam peran nya sebagai kader TB dalam melakukan komunikasi kepada masyarakat dan melakukan pencatatan serta pelaporan yang tepat kepada puskesmas. Peran kader dalam berkomunikasi bermanfaat dalam mempengaruhi masyarakat untuk melakukan pemeriksaan dan mengkonsumsi obat TB sedangkan pencatatan dan pelaporan TB berfungsi untuk mencatat segala kegaiatan yang telah dilakukan kader seperti jumlah masyarakat yang di edukasi, capaian suspek yang di rujuk ke fasilitas pelayanan kesehatan, capaian pasien TB yang didampingi, Pasien TB yang berhasil sembuh selama pendampingan. Pencatatan dan Pelaporan ini dapat memudahkan puskesmas dalam mengevaluasi kinerja kader.

Dari Penelitian Desi indra yani, et al (2018) tentang Gambaran Pelaksanaan Peran Kader tuberkulosis pada program dots di Kecamatan bandung kulon menemukan bahwa peran kader sebagai pemberi penyuluhan tentang penyakit TB dengan baik yaitu sebanyak $68,2 \%$ sisanya $31,8 \%$ yang melaksanakan tugas sebagai pemberi penyuluhan tidak baik (Yani, Hidayat and Sari, 2018), Dari penelitian ini diketahui bahwa ada sebagian kader memberikan penyuluhan tidak baik kemampuan kader ini dapat diperoleh dari minimnya pengetahuan dan skill komunikasi yang kurang baik. Sedangkan penelitian yang dilakukan Ernirita (2010) menyatakan bahwa peran motivator meningkatkan kepatuhan penderita TB teratur minum obat 1,29 kali lebih besar dibandingkan tidak ada peran motivator (Ernirita, 2010). Penelitian diatas memberikan gambaran tentang pentingnya melatih komunikasi agar dapat berperan menjadi motivator agar pasien teratur minum obat sehingga berdampak pada penemuan kasus yang tinggi, kesembuhan penderita semakin tinggi yang tentunya akan menurunkan risiko penularan TB di tambah dengan pencatatan dan Pelaporan yang baik oleh kader akan memudahkan puskesmas 
mengevaluasi kinerja dan kemajuan kader-kader TB di lapangan.

\section{Kesimpulan}

Berdasarkan kegiatan pengabdian yang sudah dilakukan dalam program ini maka dapat disimpulkan bahwa kegiatan optimalisasi kemampuan kader TB dapat meningkatkan wawasan pengetahuan kader tentang TB dan peran kader TB, komunikasi serta pencatatan dan pelaporan TB. Dengan pelatihan ini peran kader TB akan lebih optimal karena kader telah dibekali pengetahuan yang kuat, komunikasi yang baik, serta pencatatan dan pelaporan kader yang baik. Sehingga peran kader TB di lapangan dalam penanggulanan TB, serta mendampingi penderita TB dapat berjalan maksimal. Disarankan Pihak puskesmas dapat selalu memantau dan mengevaluasi kinerja kader sehingga penularan dan pengendalian TB dapat di tekan melalui peran optimal kader Pembinaan kader oleh puskesmas dan memberikan reward terhadap kinerja kader yang baik.

\section{Pengakuan/Acknowledgement}

Tim pengabdian mengucapkan terima kasih kepada LPPM Universitas Muhammadiyah Pontianak, Kepala puskesmas Sui Kakap, Kepala Desa Kalimas dan warga Desa Kalimas sebagai mitra yang telah membantu koordinasi dan pelaksanaan program ini.

\section{Daftar Referensi}

Al-Maniri. Al Rawas, F. Al-Ajmi. et al. (2008) 'Tuberculosis suspicion and knowledge among private and public general practitioners: Questionnaire Based Study in Oman', BMC public health, 8, p. 177. doi: 10.1186/14712458-8-177.

Boy, E. et al. (2015) 'Efektifitas Pelatihan Kader Kesehatan dalam Penanganan Tuberkulosis di Wilayah Binaan', Efektifitas Pelatihan Kader Kesehatan dalam Penanganan Tuberkulosis di Wilayah Binaan, 4(2), pp. 83-89. doi: 10.22146/jpki.25274.

Dinas Kesehatan Provinsi Kalimantan Barat (2019) 'Provinsi Kesehatan

Kalimantan Barat Tahun 2018'. Available at: 
https://www.kemkes.go.id/resources/download/profil/PROFIL_KES_PR OVINSI_2018/20_Kalbar_2018.pdf.

Ernirita (2010) 'Universitas indonesia', Tesis Universitas Indonesia (Tidak di publikasikan). Available at: http://lib.ui.ac.id/file?file=digital/20307972-T 31411-Pengaruh motivator-full text.pdf.

Kemenkes RI (2017) 'Kebijakan Program Penanggulangan Tuberkulosis Indonesia', Modul Pencegahan Dan Pengendalian Penyakit, pp. 1-23. Available at:

http://www.ljjkesehatan.kemkes.go.id/pluginfile.php/4602/coursecat/description/Modul Kebijakan Penanggulangan TB 2017.pdf.

Kemenkes RI (2020) Situasi TB di Indonesia. Available at: https://tbindonesia.or.id/informasi/tentang-TB/situasi-TB-di-indonesia-2/. Puskesmas sui kakap (2018) Profil Puskesmas Sui Kakap Tahun 2018.

Wahyudi, E. (2010) 'Hubungan pengetahuan, sikap dan motivasi kader dengan penemuan suspek tuberkulosis paru Di Puskesmas Sanankulon', Program pasca sarjana sebelas Maret (Tidak di Publikasikan).

WHO (2019) Global tuberculosis report 2019. Geneva. Available at: https://apps.who.int/iris/bitstream/handle/10665/329368/9789241565714 -eng.pdf?ua $=1$.

Yani, D. I., Hidayat, R. A. and Sari, C. W. M. (2018) 'Gambaran Pelaksanaan Peran Kader Tuberkulosis Pada Program Dots Di Kecamatan Bandung Kulon', Jurnal Keperawatan Komprehensif, 4(2), p. 58. doi: 10.33755/jkk.v4i2.102. 